\title{
Design and simulation on cast metal matrix composite by investment casting
}

\begin{abstract}
Metal Matrix Composite (MMC) is produced normally by melting the matrix material in a vessel and the molten metal is stirred systematically to form a vortex, and then the reinforcement particles are introduced through the side of vortex formed. However, this approach has disadvantages, mainly arising from the particle addition and the stirring method. There is certainly local solidification of the melt induced by the particles during particle addition. This condition increases the viscosity of the slurry and appears as air pockets between the particles. Moreover, the rate of particle addition needs to be slowed down particularly when the volume fraction of the particles to used increases. This study proposes the new methodology of producing cast MMC by investment casting. Deformations of the die-wax and shell alloy systems are considered in a coupled manner, but the coupled deformation of the wax-shell system is not included. Therefore, this study presents the tasks pertaining to metal matrix composites and their interactions. As a result, the work on wax and wax-die interactions is discussed. This study presents the use of computer programs for determining the wax pattern dimensions based on three-dimensional finite-element simulations. The model for coupled thermal and mechanical analysis is developed by ProCAST. The wax model is described. The following factors are considered in the analysis: (1) the restraint due to geometrical features in the metal die; and (2) process parameters such as dwell time, die/platen temperature, injection pressure, and injection temperature.
\end{abstract}

Keyword: Design; Simulation; Compressor; Metal matrix composite; Investment casting 